УДК 581.9(575.2)

\title{
СТАТЬЯ
}

\author{
БИОЛОГИЧЕСКИЕ РЕСУРСЫ ПЛОДОВ БАРБАРИСА, \\ ШИПОВНИКА, РЯБИНЫ В ПРЕДГОРНЫХ И ГОРНЫХ РАЙОНАХ \\ ИССЫК-КУЛЬСКОЙ КОТЛОВИНЫ КЫРГЫЗСТАНА \\ ${ }^{1}$ Шалпыков К.Т., ${ }^{1}$ Рогова Н.А., ${ }^{1}$ Долотбаков А.К., ${ }^{2}$ Кайыркулова А.К. \\ ${ }^{1}$ Институт химии и фитотехнологий Национальной академии наук \\ Кыргызской республики, Бишкек, e-mail: alhor6464@таil.ru; \\ ${ }^{2}$ Кыргызская государственная медииинская академия им. И.К. Ахунбаева, \\ Биикек, e-mail: tanzania_91@mail.ru
}

\begin{abstract}
В данной статье представлены материалы экспедиционных исследований по определению биологических ресурсов барбариса, шиповника и рябины в предгорных и горных районах Иссык-Кульской котловины Кыргызстана. Исследования показали, что наибольшую площадь занимает барбарис круглоплодный - 2189 га, в 2 раза меньшую - 1004,3 га - шиповник Альберта и всего 165 га - рябина тянь-шаньская. Биологический запас плодов барбариса составляет 93,27 т, эксплуатационный - на треть меньше - 61,54 т. В ущелье Каракол установлена наибольшая площадь барбариса - 384 га с биологическим запасом всего 6,49 т, в то время как в ущ. Чон Ак-Суу на площади 300 га биологический запас плодов составляет 30 т. Эксплуатационный запас в этом местообитании - 19,8 т. Продуктивность местообитаний от 13,6 до 100 кг/ га. Биологический запас шиповника Альберта на всех изученных участках составляет 26,02 т, а эксплуатационный - 17,26 т. Максимальный биологический запас $(18,9$ т) нами отмечен в лесничестве Жууку в Жети-Огузском лесном хозяйстве на площади 570 га. Эксплуатационный запас - 12,47 т. Выявленный запас плодов рябины тянь-шаньской на площади 165 га обеспечивает общий биологический запас плодов 36,84 т и эксплуатационный 24,31 т. Таким образом, в предгорных и горных районах Иссык-Кульской котловины Кыргызстана нами обнаружены промышленно значимые объемы плодов барбариса, шиповника и рябины. Этими данными могут воспользоваться заготовительные учреждения и организации, также перерабатывающие фармацевтические и промышленные предприятия Кыргызстана.
\end{abstract}

Ключевые слова: биологический запас, эксплуатационный запас, барбарис, шиповник, рябина

\section{BIOLOGICAL RESOURCES OF FRUITS OF BARBARIS, ROSE, ROWAN IN THE FOOTHLAND AND MOUNTAIN AREAS OF THE ISSYK-KUL AREA IN KYRGYZSTAN}

\author{
${ }^{1}$ Shalpykov K.T., ${ }^{1}$ Rogova N.A., ${ }^{1}$ Dolotbakov A.K., ${ }^{2}$ Kayyrkulova A.K. \\ ${ }^{1}$ Institute of Chemistry and Phytotechnology, National Academy of Sciences \\ of the Kyrgyz Republic, Bishkek, e-mail: alhor6464@mail.ru; \\ ${ }^{2}$ Kyrgyz State Medical Academy named after I.K. Akhunbaev, Bishkek, e-mail: tanzania_91@mail.ru
}

\begin{abstract}
This article presents the materials of expeditionary studies to determine the biological resources of barberry, wild rose and mountain rowan in the foothill and mountainous regions of the Issyk-Kul basin of Kyrgyzstan. Studies have shown that the largest area is occupied by the round barberry -2189 hectares, 2 times less -1004.3 hectares Albert's rose hips and only 165 hectares - Tien Shan mountain rowan. The biological reserve of barberry fruits is 93.27 tons, the operational one is less by a third - 61.54 tons. The largest area of barberry is established in the Karakol gorge - 384 hectares with a biological reserve of only 6.49 tons, while in the gorge of Chon Ak-Suu on an area of 300 hectares biological stock of fruits is -30 tons. The operational stock in this habitat is 19.8 tons. The productivity of habitats is about 13.6 to $100 \mathrm{~kg} /$ ha. The biological stock of Albert's rose hips in all the studied plots is 26.02 tons, and the operational one is 17.26 tons. The maximum biological stock we have noted is 18.9 tons in the Zhuuku forestry in the Jeti-Oguz forestry on an area of 570 hectares. The operational reserve is 12.47 tons. The revealed reserve of Tyanshanskaya mountain rowan tree on an area of 165 hectares provides a total biological reserve of fruits of 36.84 tons and an operational reserve of 24.31 tons. Thus, in the foothill and mountainous regions of the Issyk-Kul depression of Kyrgyzstan, we have found-significant volumes of fruits of barberry, rose hips and mountain rowan. These data can be used by procurement institutions and organizations that also process pharmaceutical and industrial enterprises in Kyrgyzstan.
\end{abstract}

Keywords: biological resources, operational reserve, barberry, rose, rowan

В Кыргызстане произрастает значительное количество древесно-кустарниковых видов, плоды которых активно заготавливают для использования с лекарственной и пищевой целью. К таким видам относят, прежде всего, различные виды барбариса, шиповника и рябины. Плоды их содержат определенное количество витаминов, микроэлементов, органических кислот и других полезных составляющих. Используют плоды в свежем, высушенном, замороженном и переработанном виде как лекарственное средство и для употребления в пищу. 
Потребность в лекарственном и особенно в пищевом сырье неуклонно возрастает. Постоянно расширяется ассортимент продуктов, получаемых из дикорастущих плодов. Незначительная часть их используется местным населением.

В связи с бессистемной заготовкой постепенно уменьшается количество дикорастущего плодового сырья. Исходя из этого, возникает необходимость в регулировании заготовки дикорастущих плодов, определении их биологического и эксплуатационного запасов.

Барбарис - кустарник из семейства Барбарисовые Berberidaceae. В Прииссыккулье произрастает один вид - барбарис круглоплодный Berberis sphaerocarpa Kar.et Kir. [1], который распространен по горным долинам и каменистым склонам гор. Цветет в мае-июне, плодоносит в августе-сентябре [2].

Плоды барбариса содержат сахара, органические кислоты (яблочную, винную, лимонную), пектин, дубильные и красящие вещества, витамин С. В народной медицине плоды барбариса используют как жаропонижающее и жаждоутоляющее средство, а также как приправу к пище.

Шиповник - кустарник из семейства Розоцветные Rosaceae. В ущельях, спускающихся к котловине оз. Иссык-Куль, произрастает 6 видов шиповника, из которых для заготовки используется преимущественно один вид - шиповник Альберта (Rosa alberti Regel), который распространен в лесах и на их опушках, среди зарослей кустарников по склонам гор и в поймах рек. Плоды шиповника содержат витамины C, E, P, каротин, органические кислоты, пектины, дубильные вещества, в семенах содержится жирное масло [3]. Плоды широко используются в народной и научной медицине как поливитаминное средство. Препараты на их основе применяются при авитаминозе (особенно при недостатке витамина С), масло из орешков - при кожных заболеваниях и в косметологии [4].

Ранее А.К. Кудайбергеновой [5] в данном регионе отобраны формы шиповника с перспективными признаками: повышенной урожайностью кустов, размером гипантиев, краткостью вегетации, малошиповатостью побегов, повышенной устойчивостью к болезням и вредителям, устойчивостью к засухе и низкой температуре, высокому содержанию аскорбиновой кислоты.

Рябина. В Прииссыккулье произрастает один вид рябины - рябина тянь-шанская (Sorbus tianschanica Rupr.) из семейства розоцветные Rosaceae. Цветет в мае-июле, плодоносит в августе-сентябре [2]. Она рас- пространена до верхних пределов произрастания древесно-кустарниковой растительности на высоте от 1953 до 2359 м н. у. м. Рябина тянь-шанская - дерево высотой 3-5 м. Сырьем для заготовки являются плоды, которые содержат витамины С и A, каротин, органические кислоты, дубильные вещества. Они применяются как витаминное средство, особенно при недостатке каротина, и при заболеваниях печени.

Целью исследования является выявление промышленно значимых территорий дикорастущих плодов барбариса, шиповника и рябины в предгорных и горных районах Иссык-Кульской котловины Кыргызстана.

\section{Материалы и методы исследования}

В 2017 и в 2019 гг. нами были обследованы ущелья северного склона Терскей Ала-Тоо и южного склона Кунгей Ала-Тоо, спускающиеся к котловине оз. Иссык-Куль. Определены местообитания барбариса, шиповника и рябины, территория их распространения, установлены урожайность, биологический и эксплуатационный запасы плодов.

При проведении исследований использовалась методика М.К. Крыловой и А.И. Шретера (1986) [6], в частности метод модельных экземпляров.

\section{Результаты исследования и их обсуждение}

Ранее нами были обследованы запасы лекарственного сырья термопсиса туркестанского (Thermopsis turkestanica Gand.) и гармалы обыкновенной (Peganum harmala L.) в Иссык-Кульской котловине [7]. В данной статье представлены данные по древесно-кустарниковым растениям Иссык-Кульской котловины. В результате наших экспедиционных исследований выявлены 13 местообитаний барбариса круглоплодного площадью от 3 до 384 га каждый. Ширина массивов от 100 до 600 м, длина от 1 до 14 км. Также отмечено 9 местообитаний шиповника Альберта площадью от 3 до 300 га. Барбарис и шиповник почти во всех местообитаниях произрастают совместно на высоте от 1630 до 2673 м н. у. м. Ниже приводится краткая характеристика местообитаний, урожайность и запасы сухих плодов изучаемых видов.

1. Бассейн реки Тосор. Барбарис и шиповник произрастают на высоте 2033 м н. у. м. в караганово-шиповниковобарбарисовой ассоциации. Проективное покрытие кустарниками составляет 90\%. Растительность состоит из четырех явно выраженных ярусов. 1 ярус - барбарис круглоплодный (Berberis sphaerocarpa Kar. 
et Kir.), шиповник Альберта (Rosa alberti Regel), шиповник Беггера (Rosa beggeriana Schrenk), виды караган (Caragana sp.). 2 ярус - чий раскидистый (Achnatherum caragana Roshev). 3 ярус - полынь эстрагон (Artemisia dracunculus L.), ломонос джунгарский (Clematis songarica Bunge), полыни (Artemisia sp.), василистник простой (Thalictrum simplex L.), крапива жгучая (Urtica urens L.). 4 ярус - осоки (Carex sp.), овсяница валисская (Festuca valesiaca Gaudin), лап-

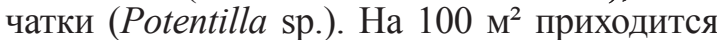
1 куст барбариса и 0,8 куста шиповника. Общая площадь барбариса - 7,8 га, шиповника $-3,3$ га. Биологический урожай плодов 0,73 т и 0,1 т соответственно (таблица).

2. Ущелье Барскоон. Барбарис распространен на высоте от 2066 до 2673 м н. У. м. Это максимальная высота произрастания данного вида. Ассоциация спирейно-барбарисово-шиповниковая. Проективное покрытие кустарниками - 90\%. Первый ярус занимает барбарис круглоплодный (Berberis sphaerocarpa Kar.et Kir.), высота которого достигает 3 м. Второй ярус высотой до 2,5 м занимают таволга зверобоелистная (Spiraea hypericifolif L.), шиповники (Rosa sp.), караганы (Caragana sp.). Третий ярус - можжевельник казацкий (Juniperus sabina L.), кизильники (Cotoneaster sp.). Четвертый ярус - разнотравье: осоки (Carex sp.), ковыль волосатик (Stipa capillata L.), овсяница валисская (Festuca valesiaca Gaudin), тимьян уменьшенный (Thymus diminutus Klok.), фломоидес горный (Phlomoides oreophilla (Kar.et Kir.) Adylov et al.), герань холмовая (Geranium collinum Steph. Ex Wild), володушка тянь-шанская (Bupleurum tianschanicum Ereyn.), подорожник большой

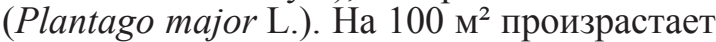
в среднем один куст барбариса с урожайностью 341 г сухих плодов. Общая площадь 288 га, биологический запас плодов - 9,82 т. На этом же участке, на площади 72 га, произрастает шиповник Альберта. На 1 га в среднем 50 кустов высотой до 2,5 м. Средний урожай плодов с 1 куста - 432 г, биологический запас-1,56 т.

3. Бассейн p. Чон-Жаргылчак. Здесь, на высоте 1630 м н. у. м. отмечен участок площадью 3 га с совместным произрастанием барбариса круглоплодного и шиповника Альберта. Биологический запас плодов 0,11 и 0,08 т соответственно (таблица).

4. В ущ. Чон Кызыл-Суу барбарис круглоплодный и шиповник Альберта произрастают на протяжении 10 км по ущелью начиная с 2251 до верхней границы на высоте 2342 м н. у. м. Ассоциация барбарисовожимолостно-шиповниковая. Проективное покрытие кустарниками $80 \% .1$ ярус - бар- барис круглоплодный. 2 ярус - жимолость (Lonicera sp.), шиповник Альберта. 3 ярус разнотравье: аконит белоустый (Aconitum leucostomum Worosch.), мята полевая (Mentha arvensis L.), манжетка отклоненноволосистая (Alchemilla retropilosa Juz), тысячелистник обыкновенный (Achillea millefolium L.). Плотность расположения кустов барбариса круглоплодного в среднем

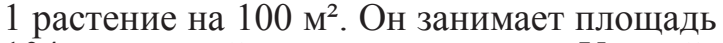
104 га по пойме и склонам гор. Урожайность кустов в среднем 340 г, биологический запас сухих плодов - 3,2 т (таблица).

Шиповник Альберта в данном местообитании встречается преимущественно по дну ущелья узкой полосой и занимает 10,4 га. Продуктивность его - 20 кг/га, биологический запас плодов - 0,21 т (таблица).

5. Бассейн p. Жети Огуз. Барбарис распространен в барбарисово-жимолостно-шиповниковой ассоциации на высоте от 1953 до 2144 м н. у. м.

Проективное покрытие кустарниками $85 \%$. Первый ярус занимает ель Шренка (Picea schrenkiana Fisch.et C.A. Mey). Во втором ярусе произрастает рябина тянь-шанская (Sorbus tianschanica Rupr.). Третий ярус - кустарники: барбарис круглоплодный (Berberis sphaerocarpa Kar.et Kir.), жимолость (Lonicera sp.), шиповники (Rosa sp.). Четвертый ярус - разнотравье: аконит белоустый (Aconitum leucostomum Worosch.), щавель кислый (Rumex acetosa L.), мята полевая (Mentha arvensis L.), манжетка отклоненноволосистая (Alchemilla retropilosa Juz.), черноголовка обыкновенная (Prunella vulgaris L.). На 100 м $^{2}$ в среднем один куст барбариса. Продуктивность местообитания - 21,3 кг/га. Площадь данного участка 152 га, биологический запас воздушно-сухих плодов - 3,24 т. Шиповник Альберта на этом участке встречается на площади 15,2 га. Биологический запас его плодов незначительный и составляет 0,24 т (таблица).

6. Жети-Огузское лесное хозяйство, лесничество Жууку. В 2019 г. выявлен новый участок с обильным произрастанием барбариса на высоте 2238-2279 м н. у. м. на площади 220 га. Ярусность и видовой состав растительности одинаковый с предыдущим участком. Проективное покрытие кустарниками 90\%. Плотность кустов барбариса здесь в 3 раза выше, чем на других участках, высота их достигает 3 м. Продуктивность массива - 108 кг/га, биологический запас плодов в воздушно-сухом виде составляет 23,76 т (таблица).

7. Урочище Арашан, Аксуйский лесхоз. Барбарис здесь отмечен на высоте от 1894 до 1964 м н. у. м. в шиповниково-барбарисовой ассоциации. Проектив- 
ное покрытие кустарниками 90\%. Первый ярус составляет рябина тянь-шанская (Sorbus tianschanica Rupr.). Второй ярус занимают шиповник Альберта (Rosa alberti Regel), шиповник Беггера (Rosa beggeriana Schrenk), и барбарис круглоплодный (Berberis sphaerocarpa Kar.et Kir.). Третий ярус - разнотравье: ежа сборная (Dactylis glomerata L.), морковь обыкновенная (Daucus carota L.), цикорий обыкновенный (Cichorium intybus L.), фломоидес горный (Phlomoides oreophilla (Kar.et Kir.) Adylov et al.), клевер луговой (Trifolium pratense L.), тысячелистник обыкновенный (Achillea millefolium L.), котовник венгерский (Nepeta pannonica L.),полынь эстрагон (Artemisia dracunculus L.), осоки (Carex sp.), клевер земляничный (Trifolium fragiferum L.). На 100 м² отмечен 1, реже 2 куста барбариса высотой 2,5-3 м. Средний урожай сухих плодов с одного куста - 910 г. Продуктивность массива с 1 га в среднем, 136,5 кг/га плодов, площадь барбариса - 180 га, биологический запас плодов - 24,57 т (таблица).

Запасы воздушно-сухого сырья плодов барбариса, шиповника и рябины в Иссык-Кульской котловине

\begin{tabular}{|c|c|c|c|c|c|}
\hline $\begin{array}{l}\text { № } \\
\Pi / \Pi\end{array}$ & Местность & \begin{tabular}{|l} 
Площадь, \\
га
\end{tabular} & $\begin{array}{l}\text { Продуктив- } \\
\text { ность, кг/га }\end{array}$ & $\begin{array}{l}\text { Биологиче- } \\
\text { ский запас, т }\end{array}$ & $\begin{array}{l}\text { Эксплуатаци- } \\
\text { онный запас, т }\end{array}$ \\
\hline \multicolumn{6}{|c|}{ Барбарис } \\
\hline 1 & Бассейн р. Тосор & 7,8 & 93,8 & 0,73 & 0,48 \\
\hline 2 & Ущ. Барскоон & 288 & 34,1 & 9,82 & 6,48 \\
\hline 3 & Бас. p. Чон-Жаргылчак & 3 & 36,0 & 0,11 & 0,07 \\
\hline 4 & Ущ. Чон Кызыл-Суу & 104 & 30,0 & 3,12 & 2,06 \\
\hline 5 & Бас. р. Жети-Огуз & 152 & 21,3 & 3,24 & 2,14 \\
\hline 6 & Жети-Огузское лесное хозяйство. Жууку & 220 & 108 & 23,76 & 15,68 \\
\hline 7 & Ур. Арашан, Ак-Суйский лесхоз & 180 & 13,6 & 2,46 & 1,62 \\
\hline 8 & Ущ. Каракол & 384 & 16,9 & 6,49 & 4,28 \\
\hline 9 & Бас. p. Ак- Суу & 110 & 21,3 & 2,34 & 1,54 \\
\hline 10 & $\begin{array}{l}\text { С. Боз-Учук, северный берег оз. Иссык- } \\
\text { Куль }\end{array}$ & 100 & 16 & 1,60 & 1,06 \\
\hline 11 & Бас. p. Жергалан & 60 & 20 & 1,20 & 0,79 \\
\hline 12 & $\begin{array}{l}\text { Ущ. Чон Ак-Суу, Григорьевское лесни- } \\
\text { чество }\end{array}$ & 300 & 100 & 30,00 & 19,80 \\
\hline \multirow[t]{2}{*}{13} & Семеновское ущ., начало & 280 & 30 & 8,40 & 5,54 \\
\hline & Итого: & 2189 & & 93,27 & 61,54 \\
\hline \multicolumn{6}{|c|}{ Шиповник } \\
\hline 1 & Бас. р. Тосор, пойма & 3,3 & 30 & 0,10 & 0,07 \\
\hline 2 & Ущ. Барскоон & 72 & 21,6 & 1,56 & 1,11 \\
\hline 3 & Бас. p. Чон-Жаргылчак & 3 & 25,2 & 0,08 & 0,05 \\
\hline 4 & Ущ. Чон Кызыл-Суу & 10,4 & 20,0 & 0,21 & 0,14 \\
\hline 5 & Жети-Огузское лесное хозяйство. Жууку & 570 & 86,4 & 18,90 & 12,47 \\
\hline 6 & Бас. р. Жети-Огуз & 15,2 & 15,6 & 0,24 & 0,16 \\
\hline 7 & Ущ. Каракол & 38,4 & 21,6 & 0,83 & 0,55 \\
\hline 8 & $\begin{array}{l}\text { Ущ. Чон Ак-Суу, Григорьевское лесни- } \\
\text { чество }\end{array}$ & 300 & 12,0 & 3,60 & 2,38 \\
\hline \multirow[t]{2}{*}{9} & Семеновское ущ., начало & 28 & 18 & 0,50 & 0,33 \\
\hline & Итого: & 1040,3 & & 26,02 & 17,26 \\
\hline \multicolumn{6}{|c|}{ Рябина } \\
\hline 1 & Бас. р. Жети-Огуз & 4 & 8,2 & 0,03 & 0,02 \\
\hline 2 & Семеновское ущ. верх & 3 & 810 & 2,40 & 1,68 \\
\hline 3 & Верхнее течение р. Каркыра & 22 & 15,0 & 0,33 & 0,22 \\
\hline \multirow[t]{2}{*}{4} & Ущ. Жылуу-Суу, верховье & 134 & 272 & 36,40 & 24,02 \\
\hline & Итого: & 165 & & 36,84 & 24,31 \\
\hline
\end{tabular}


8. Ущу. Каракол. Барбарис и шиповник произрастают на высоте от 1935 до 2172 м н. у. м. Ассоциация и растительность идентичны ущелью Арашан. На 100 м² барбариса 2 куста, шиповника - в 4 раза меньше. Барбарис занимает 384 га, шиповник - в 10 раз меньше. Продуктивность участка барбариса - 16,9 кг/га, шиповника 21,6 кг/га, биологический запас плодов 6,49 и 0,83 т соответственно (таблица).

9. Бассейн р. Аксуу. Барбарис встречается на высоте от 1881 до 2033 м н. у. м. на площади 110 га в шиповниково-барбарисовой ассоциации. Проективное покрытие кустарниками $80 \%$. Первый ярус - рябина тянь-шанская. Второй ярус занимает шиповник Беггера и барбарис круглоплодный. Третий ярус - разнотравье: тысячелистник обыкновенный (Achillea millefolium L.), душица обыкновенная (Origanum vulgare L.), крапива двудомная (Urtica dioica L.) совместно с крапивой жгучей (Urtica urens L.), полынь эстрагон (Artemisia dracunculus L.), цикорий обыкновенный (Cichorium intybus L.). Продуктивность участка- 21,25 кг/га, биологический запас сухих плодов - 2,34 т.

10. Местность выше с. Боз-Учук, северный берег оз. Иссык-Куль. Барбарис произрастает на высоте 1899-2192 м н. у. м. на площади 100 га. Ассоциация шиповниково- жимолостно-барбарисовая. Проективное покрытие кустарниками $80 \%$. 1 ярус кустарники: шиповник Беггера, барбарис круглоплодный, жимолость узкоцветковая (Lonicera stenantha Pojark.) и мелколистная (L. Microphilla Willd. T. Schult.), смородина Мейера (Ribes meyeri Maxim). 3 ярус разнотравье: крапива двудомная (Urtica dioica L.), аконит белоустый (Aconitum leucostomum Worosch.), душица обыкновенная (Origanum vulare L.), полынь эстрагон (Artemisia dracunculus L.), одуванчик лекарственный (Taraxacum officinalis L.). Ha 1 га приходится в среднем 80 кустов барбариса круглоплодного с урожайностью 200 г сухих плодов. Биологический запас плодов 1,6 т (таблица).

11. Бассейн р. Жергалан. Продуктивный массив барбариса круглоплодного расположен на высоте от 1977 до 2149 м н. у. м. по обе стороны реки на площади 60 га. Coвместно с барбарисом произрастает незначительное количество шиповника Альберта. Проективное покрытие кустарниками $75 \%$. Разнотравье состоит в основном из лекарственных растений: аконита белоустого, чемерицы Лобеля, крапивы двудомной, душицы обыкновенной. На 1 га до 80 кустов барбариса, продуктивность 20 кг/га плодов, биологический запас - 1,2 т (таблица).
12. Ущ̧. Чон-Ак-Суy. Участок барбариса и шиповника, пригодный для заготовки, занимает площадь 300 га по всему ущелью по обе стороны речки на протяжении 10 км. Растительность в этом ущелье по ботаническому составу похожа на растительность предыдущих ущелий. Проективное покрытие кустарниками 90\%. Кусты барбариса расположены довольно компактно - на 100 м² 5-6 экземпляров. Шиповник встречается реже - 1 куст на $100 \mathrm{~m}^{2}$. Продуктивность барбариса 100 кг/га сухих плодов, шиповника - значительно ниже - 12 кг/ га. Биологический запас, соответственно 30 и 3,6 т (таблица).

13. Семеновское ущзелье. Ареал распространения барбариса и шиповника находится в пределах 1850-2359 м н. у. м. на протяжении 14 км по ущелью. Растительность идентична предыдущим местообитаниям. Барбарис занимает площадь 280 га. Шиповник Альберта встречается единичными экземплярами или куртинами по 4-5 штук на площади 28 га и растет совместно с шиповником Беггера и шиповником широкошипым, плоды которых не используются для заготовки. Продуктивность барбариса 30 кг/га, шиповника - 18 кг/га, биологический запас сухих плодов 8,4 и 0,5 т соответственно (таблица).

Нами выявлено 4 продуктивных местообитания рябины тяньшанской (таблица).

Бассейн р. Жети Огуз. Рябина произрастает на высоте 2144 м н. у. м. совместно с барбарисом круглоплодным и шиповником. На 1 га в среднем 80 деревьев, урожай сухих плодов с 1 дерева 102 г. Площадь наиболее компактного произрастания рябины 4 га. Биологический запас плодов на данном участке - 32,7 кг.

Семеновское ущуелье. Рябина растет компактной группой в верховье ущелья на высоте 2359 м н. у. м. на площади 3 га. Древесно-кустарниковая растительность представлена: 1 ярус - ель Шренка (Picea schrenkiana Fisch.et C.A. Mey.), 2 ярус рябина тяньшанская, 3 ярус - барбарис круглоплодный, шиповник, жимолость. 4 ярус - разнотравье: аконит белоустый, аконит джунгарский, крапива двудомная, клевер ползучий, подорожник большой, манжетка отклоненноволосистая. На 100 м $^{2}$ отмечено в среднем 5 (3-8) деревьев. На отдельных деревьях обильное плодоношение. Урожай с одного дерева в среднем 1620 г. Биологический урожай - 2,4 т плодов в воздушно-сухом весе.

Верхнее течение р. Каркыра. Рябина встречается по обе стороны дороги на протяжении 11 км на высоте от 2215 до 2570 м н. у. м. На склоне, спуска- 
ющемся к реке, рябина часто растет в труднодоступных местах. Общая площадь местообитания - 22 га. На 100 м $^{2}$ приходится 1 дерево с урожайностью в среднем 150 г сухих плодов, биологический запас $-0,33$ т.

Ущ.. Жьлууу-Суy. В верхней части ущелья, на высоте 2317 м н. у. м., рябина растет среди кустарниковой растительности - барбариса круглоплодного, шиповника Аль-

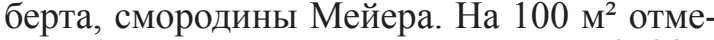
чено 1 дерево, средняя урожайность 2728 г. Площадь местообитания - 134 га, биологический урожай $-36,4$ т.

Также единичные экземпляры рябины тянь-шанской встречаются в поймах рек в ущельях Арашан, Ак-Суу, Чон Ак-Суу.

Полученные результаты по запасам дикорастущих плодов барбариса, шиповника и рябины представлены в таблице.

Как видно из таблицы, наибольшую площадь занимает барбарис круглоплодный 2189 га, в 2 раза меньшую - 1004,3 га - шиповник Альберта и всего 165 га - рябина тянь-шанская.

Биологический запас плодов барбариса составляет 93,27 т, эксплуатационный на треть меньше - 61,54 т. В ущелье Каракол установлена наибольшая площадь барбариса - 384 га с биологическим запасом всего 6,49 т, в то время как в ущ. Чон Ак-Суу на площади 300 га биологический запас плодов составляет 30 т. Эксплуатационный запас в этом местообитании 19,8 т. Продуктивность местообитаний от 13,6 до 100 кг/га.

Биологический запас шиповника Альберта на всех изученных участках составляет 26,02 т, а эксплуатационный - 17,26 т. Максимальный биологический запас $(18,9$ т) нами отмечен в лесничестве Жууку в Же-
ти-Огузском лесном хозяйстве на площади 570 га. Эксплуатационный запас $-12,47$ т.

Выявленный запас плодов рябины тяньшанской на площади 165 га обеспечивает общий биологический запас плодов 36,84 т и эксплуатационный $-24,31$ т.

\section{Заключение}

Таким образом, в предгорных и горных районах Иссык-Кульской котловины Кыргызстана нами обнаружены промышленно значимые объемы плодов барбариса, шиповника и рябины. Этими данными могут воспользоваться заготовительные учреждения и организации, также перерабатывающие фармацевтические и промышленные предприятия Кыргызстана.

\section{Список литературы}

1. Лазьков Г.А., Султанова Б.А. Кадастр флоры Кыргызстана. Сосудистые растения. Бишкек, 2014. 125 с.

2. Лазьков Г.А. Древесные растения Кыргызстана. Бишкек, 2017. 336 с.

3. Ходжиматов М. Дикорастущие лекарственные растения Таджикистана. Душанбе: Гл. научная редакция Таджикской Советской энциклопедии, 1989. 368 с.

4. Айзенман С., Зауров Д.Э., Шалпыков К.Т., Струве Л. Лекарственные растения Средней Азии: Узбекистан и Кыргызстан. Бишкек: Изд-во «Имак-Офсет», 2014, 431 с.

5. Кудайбергенова А.К. Биологические особенности Rosa acicularis Lindl. в условиях Иссык-Кульской области Кыргызстана: автореф. дис. ... канд. биол. наук. Бишкек, 2012.23 c.

6. Крылова М.К., Шретер А.И. Методические указания по изучению запасов дикорастущих лекарственных растений. М.: ВИЛР, 1986

7. Шалпыков К.Т., Рогова Н.А., Долотбаков А.К. Запасы лекарственного сырья термопсиса туркестанского (Thermopsis turkestanica Gand.) и гармалы обыкновенной (Peganum harmala L.) в Иссык-Кульской котловине Кыргызстана // Инновационное развитие экономики: материалы Второго Крымского инновационного форума. Симферополь: ИТ «АРИАЛ», 2020. С. 137-142. 